The catalogue lists by progressive serial numbers the patents awarded up to 1852, when the Patent Law Amendment Act was passed. A noticeable trend is the acceleration in the pace of invention, as judged by the number of patents awarded: between 1617 and 1650 some 130 patents were granted; a further 130 were assigned between 1650 and 1700,300 between 1700 and 1750 , 1,800 between 1750 and 1800 , and 10,000 between 1800 and 1850 . There also seems to be a pattern in the subject matter of the patents; in the seventeenth and eighteenth centuries there are numerous patents for improving the manufacture of falchions, swords, rapiers, scabbards, saltpetre and other instruments of war. Not until the 1820 s do the useful arts replace the military in the preoccupations of inventors. None the less, the patent business seems to have started out on a peaceful note; the first patent ever to be granted was to Aaron Rapburne in 1617 for "making, describing, carving, graving and printing maps of London, Westminster (and other eities)", while patent No. 2 went to the miniaturist portrait painter Nicholas Hillyard for "drawing, engraving and printing pictures and representations of his Majesty, on paper parchment and other suitable materials".

The catalogue is a fine list of names but little more. Who are all these inventors, what are their antecedente, did their inventions fail or prosper? The catalogue is clearly the raw material of a major social history that has yet to be written. But the publishers could at least have had it equipped with an index of inventions.

NICHOLAS WADE

\section{CONTROL THEORY}

Matrix Analysis of Discontinuous Control Systems

By P. V. Bromberg. Edited by J. O. Flower. Pp. x +265 . (Macdonald (Technical and Scientific): London, August 1969.) 100s.

THIs book is concerned with the application of methods of matrix calculus to the solution of probloms in discontinuous systems and so covers an aspect of control theory which is often neglected in modern texts.

The first chapter is meant as an introduction to control and describes in detail tho automatic stabilization of the course of an aircraft. It is not a good chapter and does little to help one's understanding of the problems to follow. By contrast, the second chapter is a particularly well written and excellent review of the fundamental formulae of matrix algebra and it is an essential preliminary to the subsequent chapters.

These remaining chapters cover stability, control and relay operation of discontinuous systems, but although the theory is taken to a fairly advanced level its usefulness is somewhat limited because its application is always referred to aircraft control systems. The theorems of the direct Lyapunov method are extended to discrete dynamic systems whose perturbed motion is defined in finite difference form. Stability and control in a system which uses linear pulses and finite mark/space ratio as the control functions, and also pulse and step function controllers are then discussed. The author considers the natural and forced modes of oscillation of relay control systems and determines the stability of the periodic modes and the effects of external actions and disturbances on the systems. The final results are then expressed in terms of the original parameters of the system and, throughout, the results are illustrated by the example of an aircraft control system.

Unfortunately, the presentation of the book makes for difficult reading. The book lacks layout and somehow it just seems to go on and on. This, and the excessive use of many Greek letters and subscripts making the notation unfamiliar to most British readers, make the book difficult to follow; few people will he able to pick out material relevant to their own problem from a quick flick through the pages. The different topies are not highlighted and the material is not clcarly subdivided. The book is certainly not a student textbook, even for postgraduate students, but it should be included in the library of control research groups and the specialist control groups of the computer firms and the major process industries because it does cover quite thoroughly, although heavily, a theoretical aspect of control not adoquately covered elsewhere.

MaURICE G. MÝlRoI

\section{INVISIBLE RAYS}

\section{Infrared System Engineering}

By Richard. D. Hudson, jun. Pp. xxvi+642. (Wiley (Interscience): New York and London, June 1969.) 185s.

Is the course of Sir William Herschel's observations of the Sun in 1800, he was plagued by the fact that the filters he used to protect his eyes often cracked. His investigations into the best type of filter led to his discovery of infrared radiation and to his prophetic statement, "It may be pardonable if I digress for a moment and remark that the foregoing researches ought to lead us on to others ... ". Even Herschel could never have foreseen the range of application of his "invisible rays" revealed so ably by Richard D. Hudson.

His book is highly significant for several reasons. It shows conclusively that most infrared instruments are "systems" and are best designed by an infrared systems engineer. The fact that few (if any) academic courses produce such people has forced industry to take on the job, and Hudson was asked to educate more than 450 engineers at the Hughes Aircraft Company. His courses led to the present volume, which is very nearly a masterpiece. The first fourteen chapters deal exhaustively with all the elements of an infrared system, from sourees, through the atmosphere, optics and optical modulator, to the detector, its cooling system and the electronic signal processor. In each case the discussion begins at an elementary level and proceeds clearly and logically to the frontier of present knowledge. The reader is then taken step by step through the design of a fictitious system to prove that almost all the information he needs is contained in the preceding chapters. Each chapter ends with a list of references-some 700 in all. The second part of the book classifies an enormous range of infrared applications and lists 1,400 annotated references drawn from the open literature of the past century.

So comprehensive a book can rarely have been written by one man, and the author acknowledges the assistance of many colleagues, but the book has a consistency of style and level which makes it so much better than a collection of articles by independent experts. I venture to suggest that no academic could write such a book and that we must, in future, look to enlightened industrial companies for authors. Perhaps one should say selfenlightened because the book is inevitably written from the standpoint of the US infrared industry and over its years as a standard text it will be a splendid advertisement.

If I were asked to single out a chapter for especial praise, it would be the one on optical modulators. This subject is so shrouded in secrecy that it is refreshing to see how much the author has been able to publish by the ingenious device of using the patent literature to establish that a topic is not "classified". There are, of course, some minor defects. In the very first diagram the source of infrared radiation is called the "target" and there are other examples of the predominance of military thinking. The atmosphere is said to be essentially opaque beyond $15 \mu \mathrm{m}$, despite later references to astronomy at longer wavelengths. The treatment of detectors is a little uneven; the germanium bolometer is omitted from a very useful diagram comparing detectors, although men- 